\title{
Redescrição de Cymodoce madrasensis (Srinivasan, 1959) Combinação Nova (Sphaeromatidae: Isopoda: Crustacea) de Madras, Índia.
}

\author{
Jayme de Loyola e Silva
}

Departamento de Zoologia, Universidade Federal do Paraná. Caixa Postal 19020 - 81531-990 Curitiba/PR, BRASIL. Pesquisador Bolsista do CNPq

\begin{abstract}
The author studying a male of Exosphaeroma madrasensis Srinivasan, 1959, catalog 102151 Division of Crustacea - USNM, describes and transfers the species to the genus Cymodoce Leach, 1814 establishing a new combination Cymodoce madrasensis (Srinivasan, 1959).
\end{abstract}

KEY WORDS: Isopoda, Sphaeromatidae, Cymodoce madrasensis, taxonomy, India

\section{INTRODUÇÃO}

A família Sphaeromatidae, com grande número de espécies, constitui-se de variados modelos adaptacionais. As variações morfológicas condizentes aos diversos nichos, em meios marinhos, salobros e de águas doces, possibilitam às espécies galgar novos ambientes. Entre as modificações estruturais, as mais características, nas espécies do gênero Cymodoce Leach, 1814, salientam-se na região abdominal e somente nos machos. Não significa exclusividade, desta parte do corpo dos machos, pois em inúmeras outras espécies de outros gêneros, tanto no tórax como no cefalon, aparecem formações, tão específicas, que são consideradas aberrantes. As modificações corpóreas constituem-se em aparatos adaptacionais das espécies para cada nicho peculiar.

Machos e fêmeas, deste gênero, apresentam características diferenciais, com frisante dimorfismo sexual. As fêmeas de diferentes espécies de Cymodoce apresentam muita similaridade; seguem linhagem harmônica e uniforme, praticamente, sem variações morfológicas. Depois de fertilizadas as fêmeas realizam ecdise, adquirem oostegitos e sofrem grande metamorfose nas peças bucais perdendo, totalmente, as atividades mastigadoras, o que perdura durante o período de incubação (Loyola e Silva, 1963). As variações morfológicas ornamentais que os machos de Cymodoce ostentam, diferentemente das fêmeas, aparecem como tubérculos, espinhos, dentes, lobos, cerdas, em especial, no dorso do tórax e do abdome, caracterizando cada uma das espécies e constituindo-se em bons caracteres taxonômicos. O presente trabalho teve como objetivo precípuo o enquadramento da espécie em gênero condizente com suas características.

\section{MATERIAL E MÉTODOS}

Durante o estágio de um ano, na Division of Crustacea - USNM, tivemos facilidades de trabalho laboratorial, assim como, liberdade de usar a Coleção de Sphaeromatidae (Isopoda) e preparar espécimens para a confecção dos desenhos.

O exemplar macho que utilizamos para a redescrição desta espécie encontra-se depositado na Coleção de Isopoda da Division of Crustacea of the United States National Museum, Smithsonian Institution, Washington, D.C. USA. Catálogo nº 102151.

Restringimo-nos a um único desenho, dorso abdominal, como têm feito outros autores, pois é 
a região do corpo em que as espécies do gênero Cymodoce apresentam as maiores variações morfológicas. Além da descrição dos caracteres morfológicos abdominais referimo-nos também, mesmo sem desenhos, a alguns apêndices e partes do corpo de importância taxonômica.

\section{O Gênero Cymodoce Leach, 1814}

As espécies do gênero Cymodoce, por apresentarem dobras transversas nos endópodos dos pleópodos 4 e 5 , foram incluídas no grupo dos Hemibranchiatae (Hansen, 1905). Este autor instituiu os seguintes caracteres para a diagnose do gênero: epístoma sem qualquer processo livre na fronte; maxilípodos com os palpos provido de lobos longos no quarto, quinto e sexto artículos; parte anterior do abdome sem qualquer processo mesial; fenda abdominal com lobo bem desenvolvido ou pelo menos vestigial; exópodo do terceiro pleópodo sempre biarticulado.

Mais recentemente (Harrison \& Ellis, 1991) publicaram extensiva e trabalhosa chave para os gêneros de Sphaeromatidae de Água Marinha e Salobra. Para o gênero Cymodoce constam, como principais os seguintes caracteres diagnósticos: pleotelson, pleon e região posterior do pereon normalmente com tubérculos, cristas e longas cerdas; ápice do pleotelson tridentado em vista dorsal (com uma fenda possuindo um dente mediano); exópodos dos pleópodos 4 e 5 sem dobras transversas; artículo 1 do pedúnculo da antênula com o ângulos distais não distendidos em processo agudo; placa coxal do pereonito 5 não se estendendo ventralmente mais que as outras placas coxais.

\section{RESULTADOS}

Cymodoce madrasensis (Srinivasan, 1959) combinação nova.

Diagnose. Margem posterior do $4^{\circ}$ pleonito com duas saliências, submedianas, projetadas sobre o pleotelso. Pleotelso com dois tubérculos salientes, submedianos; ápice em entalhe quadrangular com lobo robusto de extremidade bilobada; dorso basal do lobo com um tubérculo em domo, glabro e grande. Apêndice masculino do $2^{\circ}$ pleópodo, separado desde a base, ultrapassa o comprimento do próprio endópodo. Exópodo do $3^{\circ}, 4^{\circ}$ e $5^{\circ}$ pleópodos com articulação no segundo terço. Pênis composto de dois ramos estiliformes. Endópodos dos pleópodos $4^{\circ}$ e $5^{\circ}$ com dobras transversas e exópodos membranosos, sem dobras.

\section{Descrição (macho).}

Corpo. Superfície do corpo, até o $4^{\circ}$ segmento do tórax, rugosa e pontuada. Comprimento do espécime distendido, 7,5 $\mathrm{mm}$ e largura, no $5^{\circ}$ segmento torácico, $3,1 \mathrm{~mm}$. Abdome, dorsalmente, muito ornamentado.

Antênulas. Artículo peduncular normal, com os ângulos distais não distendidos em processo agudo.

Maxilípodos. Margens internas do $4^{\circ}, 5^{\circ}$ e $6^{\circ}$ artículos do palpo projetadas, internamente, em lobos alongados.

Tórax. No $5^{\circ}$ segmento há duas séries transversas de tubérculos, pouco evidentes; no $6^{\circ}$ e $7^{\circ}$ há duas séries de tubérculos, transversas, mais salientes que as do segmento anterior. Margens posteriores dos segmentos, laterais das placas coxais e tubérculos providos de cerdas finas. Margens laterais das sete placas coxais têm o mesmo alcance e as suturas, desde a $2^{\mathrm{a}}$ até a $7^{\mathrm{a}}$, nítidas, dirigidas em obliquiidade posterior; $1^{\text {a }}$ placa coxal, securiforme, com a parte anterior bem projetada, estreita, terminada em ponta e a porção posterior projetada mas terminada em ângulo obtuso; $2^{\mathrm{a}}, 3^{\mathrm{a}}$ e $4^{\text {a }}$ placas, trianguladas, de ápice estreitado terminam em ângulo obtuso; as três últimas, mais alargadas, terminam arredondadamente.

Pênis. composto de dois ramos estiliformes, justapostos, longos, com ponta aguda.

Abdome. Primeiro pleonito, faixa estreita de consistência mole, situa-se sob o $7^{\circ}$ segmento do tórax, com sutura posterior completa; as laterais alcançam apenas as suturas das placas coxais e a porção mediana, de forma trapezoidal, projeta-se, levemente, para trás. O $2^{\circ}$ pleonito, mais largo que o anterior, alcança as laterais das placas coxais torácicas; resta, da sua margem posterior, a cada lado, apenas uma sutura esquerda e outra direita; o terço central, intimamente, fusionado com o $3^{\circ}$ pleonito. Este tem o mesmo alcance da 
lateral do pleonito anterior; como vestígio da margem posterior resta uma sutura do lado direito e outra do esquerdo; a porção central, intimamente, fusionada com o pleonito seguinte. $\mathrm{O} 4^{\circ}$ pleonito tem o mesmo alcance da lateral dos dois anteriores porém mais longo e mais robusto; a margem posterior projeta-se sobre o pleotelso como duas saliências submedianas, crenuladas, cada uma com um tufo de cerdas; possui ainda um par de tubérculos, submedianos, robustos, próximos da margem posterior; a superfície dorsal revestida de tubérculos pequenos. Margens devido dois tubérculos submedianos, robustos, de base arredondada; cada tubérculo com o ápice bilobado possui cerdas curtas e longas, espinhosas; ápice do pleotelso em entalhe quadrangular, avantajado, bem visível ventralmente, com as duas extremidades bilobadas; entalhe preenchido com um acentuado lobo que o ultrapassa com a sua metade posterior e termina em dois lobos glabros, tendo ao meio cerdas longas; no dorso basal do lobo há um grande tubérculo em domo elipsóide, glabro e provido de cerdas nas laterais. Superfície dorsal

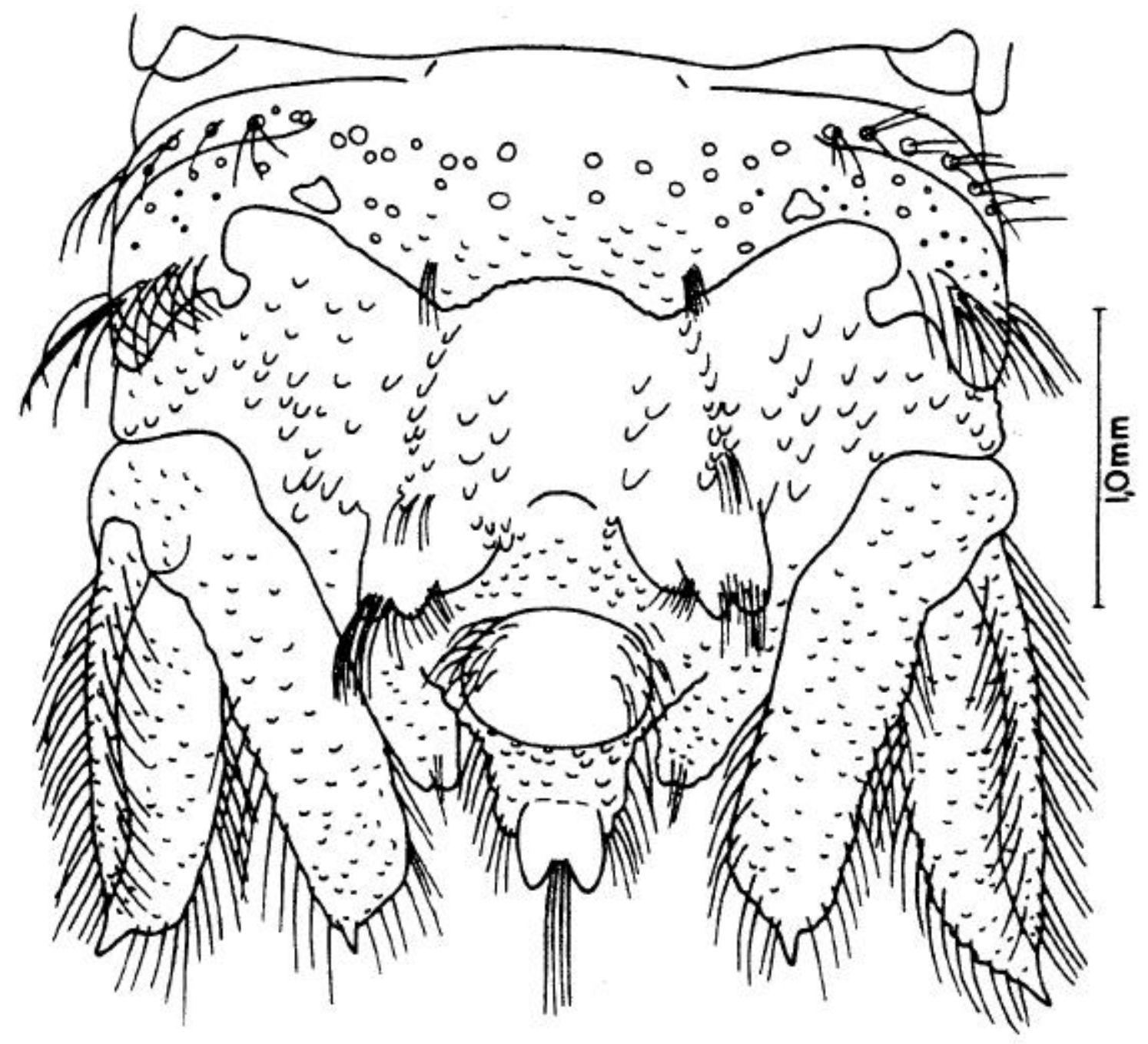

Fig. 1. Cymodoce madrasensis (Srinivasan, 1959) combinação nova. No primeiro segmento do abdome as suturas pleonitais e a margem posterior do $4^{\circ}$ pleonito com duas saliências submedianas. Pleotelso com os dois tubérculos submedianos; entalhe quadrangular com lobo mediano, tubérculo em domo e ápice bilobado. Urópodos.

laterais do $3^{\circ}$ e $4^{\circ}$ pleonitos providas de cerdas fortes. Pleotelso tem a metade anterior saliente do pleotelso revestida de pequenos tubérculos e de cerdas. 
Pleópodos. Apêndice masculino do $2^{\circ}$ pleópodo separado desde a base ultrapassa, um pouco, o comprimento do próprio endópodo. Exópodos do $3^{\circ}, 4^{\circ}$ e $5^{\circ}$ pleópodos com articulação no segundo terço. Endópodos do $4^{\circ}$ e $5^{\circ}$ pleópodos providos de dobras transversais, profundas; exópodos membranosos, isentos de dobras.

Urópodos. Ramos dos urópodos, quando encaixados, um sobre o outro, alcançam a extremidade do pleotelso. Endópodo retangulado, alongado com a porção distal, externa, projetada agudamente, em forma de espinho; com ambas as margens crenuladas, providas de cerdas; superfície dorsal revestida de pequenos tubérculos. Exópodo, quando encaixado sob o endópodo, alcança sua extremidade; margem externa, rebatida para cima, formando encaixe para conter a margem externa do endópodo; ambas as margens providas de cerdas e a interna, crenulada; toda a superfície dorsal do exópodo provida de pequenos tubérculos; porção distal termina, agudamente, em forma de espinho.

Distribuição Geográfica. Macho utilizado para descrição procedente de Madras, Índia.

Registro. Dois machos, Catálogo 102151 Division of Crustacea, USNM.

\section{DISCUSSÃO}

A espécie estudada foi transferida para Cymodoce Leach, 1814 face aos caracteres condizentes com o gênero e instituída combinação nova Cymodoce madrasensis (Srinivasan, 1959). Analisando os parâmetros de similaridade, com espécies afins do mesmo gênero, pensamos descrever a espécie, procedente de Madras, India, como nova para a ciência. Como havia passado algum tempo do estudo realizado, fizemos consulta ao Dr. Brian Kensley do USNM sobre a espécie constante catálogo 102151 USNM, e fomos informado que havia sido descrita como Exosphaeroma madrasensis Srinivasan, 1959. Dadas as dificuldades de conseguir a Revista onde o artigo foi publicado, gentilmente, o Dr. Kensley enviou-me um xerox. O desenho do abdome da espécie descrita por Srinivasan, por não ser bem fiel, difere um pouco do nosso (fig. 1). Contudo, pela descrição e registro de depósito do USNM, confirmamos tratar-se da mesma espécie.

Face a combinação nova procedemos a discussão com algumas espécies, mais afins, pertencentes ao gênero Cymodoce.

Os desenhos do abdome de $C$. truncata Leach, 1814, constantes do trabalho (Monod, 1931) mostram similaridades com C. madrasensis. $\mathrm{O}$ lobo mediano do entalhe do pleotelso, em $C$. madrasensis é robusto, ultrapassa as extremidades do entalhe $\mathrm{e}$ tem o ápice nitidamente bífido; em $C$. truncata o lobo é estreito e termina junto às extremidades laterais do entalhe e tem o ápice simples; o domo dorsal da base do lobo mediano também oferece diferenças; os dois tubérculos da porção mediana do pleotelso também estruturam-se de forma diferente. C. truncata é citada para o Atlântico oriental desde a Irlanda até Marrocos e Mediterrâneo. C. madrasensis tem como localidade típica Madras, India.

(Dumay, 1971) faz estudo comparativo dos caracteres citados por vários autores para $C$. truncata sobre os quais, em relação à espécie por nós estudada, traçaremos algumas considerações. O exemplar de $C$. madrasensis que utilizamos mede 7,5 mm de comprimento; os exemplares citados por (Dumay, 1971) variam entre 10 e 16 $\mathrm{mm}$; os urópodos de $C$. truncata ultrapassam o ápice do pleotelso e em C. madrasensis terminam junto ao ápice; $C$. madrasensis. possui um único domo elipsóide na base do lobo mediano do entalhe do telso e poucas cerdas; $C$. truncata, além de um domo cordiforme, possui um tubérculo pequeno a cada lado, perfazendo três e densamente setosos; $C$. truncata apresenta o ápice do lobo mediano truncado, enquanto, em $C$. madrasensis é, nitidamente, bífido, glabro, mais comprido que as duas terminações laterais do entalhe. O dorso do pleotelso de C. madrasensis é revestido de pequenos tubérculos. $C$. truncata ocorre na costa da Inglaterra e Mediterrâneo.

Dumay (op.cit.) apresentou um histórico da diagnose do gênero Cymodoce Leach, 1814. Salientou e comparou as principais características apresentadas por vários autores mas não instituiu diagnose nova para o gênero. 


\section{AGRADECIMENTOS}

Ao Dr. Brian Kensley do USNM pela valiosa informação sobre dados do Catálogo da espécie na Instituição. À John Simon Guggenhein Memorial Foundation, New York, USA, pela concessão de bolsa.

\section{RESUMO}

$\mathrm{O}$ autor estudou quase todas as espécies da família Sphaeromatidae (Isopoda), da Coleção de Crustacea do USNM, e a espécie constante do catálogo 102151 USNM, na época, não possuia identificação razão pela qual o autor enquadrou no gênero Cymodoce. Hoje está classificada como Exosphaeroma madrasensis Srinivasan, 1959. Este gênero não condiz com as características da espécie motivo pelo qual o autor procedeu a transferência para o gênero Cymodoce Leach, 1814, e estabeleceu nova combinação Cymodoce madrasensis (Srinivasan, 1959).

\section{REFERÊNCIAS}

Dumay, D.(1971), Révision systématique du genre Cymodoce (Isopoda Flabellifera) I. Introduction et description de deux espècies: Cymodoce truncata (Montagu) et C. (truncata) pilosa Milne-Edwards. Tethys, 3 (3): 639-654.

Hansen, H. J. (1905), On the propagation, structure and classification of the Family Sphaeromidae. Quart. Journ. Micr. Sci., 49: 69-136.

Harrison, K , \& Ellis, J. P. (1991), The Genera of the Sphaeromatidae (Crustacea: Isopoda): a Key and Distribution List. Invertebr. Taxon., 5:915-952.

Loyola e Silva, J. (1963), Metamorfoses das peças bucais em fêmeas de Cymodoce LEACH, 1814. Bol. Inst. Def. Patr. Natural, 5:1-10. BRASIL.

Monod, Th.(1931), Tanaidacés et isopodes aquatiques de I'Afrique Occidentale et Septentrionale. $\quad 3 \mathrm{e}$ partie (1) Sphaeromatidae. Mem. Soc. Sci. Nat. Maroc., 29: 1-91.
Richardson, H. (1906), Descriptions of new isopod crustaceans of the Family Sphaeromidae. Proc. U. S. Natl. Mus., 31: 1-22.

Srinivasan, T. K. (1959), On a new species of wood boring isopod, Exosphaeroma madrasensis from Madras. Journal of the T.D. and P.A. India. 5 (3):20-24.

Received: December 30, 1997; Revised: May 20, 1998; Accepted: September 28, 1998. 